\title{
Hysteresis In Unemployment: Panel Unit Roots Tests Using State Level Data
}

Ramesh Mohan, (Email: rmohan@bryant.edu), Bryant University Francis Kemegue, (Email: fkemegue@bryant.edu), Bryant University Fahlino Sjuib, (Email: fsjuib@frc.mass.edu), Framingham State College

\begin{abstract}
Most studies that use classical unit-root tests in OECD countries support the unemployment hysteresis hypothesis. However, similar classical tests performed on US data yield mixed results, uncovering specification issues. This study uses a number of panel unit root tests, which are known to overcome specification problems, to check the existence of hysteresis in unemployment data from three Massachusetts regions. The empirical results strongly reject a unit root in the unemployment rates, refuting the unemployment hysteresis hypothesis.
\end{abstract}

Keywords: Hysteresis, Unemployment, panel unit root test.

\subsection{INTRODUCTION}

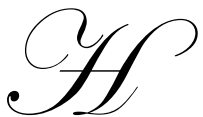

ysteresis refers to the influence of current market shocks on future market equilibrium conditions. As introduced by Phelps (1972), unemployment hysteresis describes a sustained unemployment after a transitory shock. In essence, the effect of the shock gets built into the natural rate of unemployment resulting in changing the long run equilibrium. In general, there are two theoretical justifications for the existence of hysteresis. The first justification is based on market rigidities. It is the view used in the insideroutsider model of Lindbeck and Snower (1988). This view stipulates that the existence of hysteresis is due to the power of labor unions that keep the equilibrium wage high, and therefore increases unemployment. Market rigidity is also the basis for the human capital effect (Layard et. al, 1991). The second justification for hysteresis is based on the anticipation of inflation in a Phillips Curve approach, whereby downward pressures on inflation lead to sustained high unemployment (Hall, 1979).

In a more general sense, a change in the natural rate of unemployment can occur due to: (i) fluctuations in macroeconomic variables (Blanchard and Wolfers, 1999; Phelps, 1999), or (ii) institutional changes that affect employment conditions, such as labor market regulations. Hysteresis causes unemployment dynamic to be a nonstationary process that does not revert to its long run equilibrium. On the contrary, rejecting hysteresis implies that the unemployment dynamic is a stationary process that is flexible enough to easily revert to its long run equilibrium. Nevertheless, in the case of near hysteresis (persistence), market rigidities cause unemployment to remain in the economy because the speed of adjustment to the long run equilibrium level is slower. Theoretically, testing for hysteresis becomes synonymous with testing for stationarity in the data.

This paper empirically tests the existence of hysteresis in Massachusetts monthly unemployment data for the period of 1990 to 2006. Unlike many regions in the US, Massachusetts has been recognized for having a dramatic turnaround in its economy since the 1970s. In the early 1970s, soaring unemployment, staggering state budget overruns, and tough competition beyond its borders had driven Massachusetts' aging economy to its knees. In the 1980s, the state's robust high-tech based economy and its record low unemployment had focused worldwide attention on what has been called the "miraculous" economic revival (Lampe, 1988). Massachusetts has been one of the most important centers of technological innovation in the United States and a host of high-technology research 
and enterprise. However, with the melting down of the information technology sectors in the beginning of the $21^{\text {st }}$ century and a slowing down in the overall economic activity in the United States, Massachusetts experiences another dramatic economic hardship, which logically leads to renewed interest in the recent behavior of macroeconomic variables such as unemployment.

This paper contributes to the literature in two ways. First, the paper employs and compares four panel unit roots tests of monthly data from the period of 1990:1 to 2006:8. Second, the study tests the validity of the unemployment hysteresis hypothesis using regional data for the state of Massachusetts. To our knowledge, this is the first time U.S. monthly state-level regional data has been applied to test unemployment hysteresis. The rest of the paper is organized as follows. Section 2 briefly discusses the literature review. Section 3 explains the data and econometric methodology. Section 4 reports the empirical results, and section 5 presents some concluding remarks.

\subsection{LITERATURE REVIEW}

An extensive empirical literature has developed around the topic of unemployment hysteresis during the past two decades. In general, these research features various unit root tests checking the existence of hysteresis in unemployment data. Despite diversity of country characteristics and unemployment experience, most studies based on classical unit root tests find evidence of hysteresis or at least persistence in unemployment in Europe (Blanchard and Summers, 1986; Mitchell, 1993; Roed, 1996). On the other hand, similar methodology yields mixed evidence in the US, with most research concluding non-existence of hysteresis (Mitchell, 1993; Breitung, 1994), and some findings support the hysteresis hypothesis when considering different specifications (Nelson and Plosser, 1982; Perron, 1989; Roed, 1996). More recent unit root tests attempt to overcome the specification problem. Song and Wu (1997), for example, using the Levin and Lin (1992) test found that unemployment rates in the US are stationary. Their result is confirmed by Leon-Ledesma (2002) by using the Im, Pesaran and Shin (IPS) test and found that U.S. unemployment data is stationary. Many other advanced panel unit root tests have been used for European and Australian data but not for the US data (Moon, Perron, and Phillips, 2006). This paper attempts to empirically test US state level data using four panel unit root tests that are known to correct the specification issues.

\subsection{DATA AND EMPIRICAL METHODOLOGY}

As mentioned above, the current study used monthly data from 1990:1 to 2006:8. All data came from the MetroWest Economic Research Center (MERC) for three regions in the state of Massachusetts, namely: South Shore (SS), Blackstone Valley (BV), and I-495 MetroWest Corridor (I495).

Consistent with the calculation of U.S. Bureau of Labor Statistics, the unemployment rate in this study is household-based and reflects the labor market status of residents of each region. Thus, the unemployment rate is a measure of the amount of unutilized labor in the region and represents the proportion of unemployed individuals in the labor force. The calculation comes from monthly estimates of the size of the local labor force and the number of employed and unemployed residents for all regions under study.

A number of tests are available in the literature to test for panel unit roots; such as Im, Pesaran and Shin (1997), ADF-Fisher (Maddala and Wu, 1999); Breitung (2000); and Levin, Lin and Chu (2002). ${ }^{1}$ The details of various common unit root tests are given below. For panel data, an AR (1) model can be written as follows:

$U_{i t}=\rho_{i} U_{i t-1}+d_{i t} \delta_{i}+\varepsilon_{i t}$

where $\mathrm{U}$ is the unemployment rate in region $i=1, \ldots \ldots \mathrm{N}$, over periods $\mathrm{t}=1, \ldots \ldots, \mathrm{T}(\mathrm{i})$.

$\mathrm{d}_{\mathrm{it}}$ is the exogenous variables (including fixed effects or individual trends).

$\rho_{\mathrm{i}}$ are the autoregressive coefficients. ${ }^{2}$

$\varepsilon_{\mathrm{it}}$ is the error term with independent idiosyncratic disturbance.

\footnotetext{
${ }^{1}$ The original paper by Levin and Lin (1992) was republished as Levin, Lin and Chu- LLC (2002).

${ }^{2}$ If $\left|\rho_{\mathrm{i}}\right|<1, \mathrm{U}_{\mathrm{i}}$ is trend-stationary or weakly stationary, and if $\left|\rho_{\mathrm{i}}\right|=1 \mathrm{U}_{\mathrm{i}}$ contains a unit root. LLC, and Breitung tests assume that $\rho_{\mathrm{i}=} \rho$ for all implying persistence parameters are common across cross-sections. However for the IPS test, $\rho_{\mathrm{i}}$ differ across crosssections.
} 
Consider the following ADF specification:

$\Delta U_{i t}=\alpha U_{i t-1}+\sum_{k=1}^{\rho i} \gamma_{i k} \Delta U_{i t-k}+d_{i t}^{\prime} \delta+\varepsilon_{i t}$

where $\alpha=\rho-1$, and allow $\rho_{\mathrm{i}}$ to differ across cross-sections.

Hypothesis testing can be specified as follows:

Null hypothesis $\mathrm{H}_{\mathrm{O}}: \alpha=0$ (there is a unit root) and the alternative is

$\mathrm{H}_{1}: \alpha<0$ (no unit root).

\section{Levin, Lin And Chu (LLC)}

Levin, Lin and Chu (2002) define $\Delta \bar{U}_{i t}$ by taking $\Delta U_{i t}$ and eliminating the autocorrelations and deterministic components:

$\Delta \bar{U}_{i t}=\Delta U_{i t}-\sum_{k=1}^{\rho i} \hat{\gamma}_{i k} \Delta U_{i t-k}+d^{\prime}{ }_{i t} \hat{\delta}$

Similarly $\Delta \bar{U}_{i t-1}$ can be written as

$\bar{U}_{i t-1}=U_{i t-1}-\sum_{k=1}^{\rho i} \hat{\gamma}_{i k} \Delta U_{i t-k}+d^{\prime}{ }_{i t} \hat{\delta}$

Then, the equations are divided by the standard error $\left(s_{\mathrm{i}}\right)$ to obtain proxies:

$\Delta \bar{U}_{i t}=\Delta U_{i t} / s_{i}$

$\bar{U}_{i t-1}=U_{i t-1} / s_{i}$

Finally, the coefficient $\alpha$ is obtained from the pooled proxy equation above:

$\Delta \bar{U}_{i t}=\alpha U_{i t}+\eta_{i t}$

The modified t-statistic $\left(\mathrm{t}_{\alpha^{*}}\right)$ is

$t_{\alpha^{*}}=\frac{\left.t_{\alpha}-(N T) S_{N} \sigma^{-2} \operatorname{se}(\alpha) \mu_{m T^{*}}\right)}{\sigma_{m T^{*}}} \longrightarrow N(0,1)$

where $t_{\alpha}$ is the standard t-statistic for $\alpha=0$.

$\sigma^{2}$ is the estimated variance of the error term $\eta$

$\operatorname{se}(\alpha)$ is the standard error of $\alpha$

\section{Breitung}

The Breitung test differ in two ways compared to LLC. First, to generate the standardized process, the autoregressive component of the model is removed:

$\Delta U_{i t}=\left(\Delta U_{i t}-\sum_{k=1}^{\rho i} \gamma_{i k} \Delta U_{i t-k}\right) / s_{i}$ 
$\tilde{U}_{i t-1}=\left(U_{i t-1}+\sum_{k=1}^{\rho i} \gamma_{i k} \Delta U_{i t-k}\right) / s_{i}$

where $\mathrm{s}_{\mathrm{i}}$ are the estimated standard errors. Second, the proxies are transformed and detrended:

$\Delta U_{i t}=\sqrt{\frac{(T-t)}{T-t+1}}\left(\Delta U_{i t} \frac{\Delta U_{i t+1}+\ldots+\Delta U_{i t+T}}{T-t}\right)$

$\Delta U_{i t-1^{*}}=U_{i t-1}-c_{i t}$

Where

$c_{i t}=\left\{\begin{array}{cl}0 & \text { if no intercept or trend } \\ U_{i 1} & \text { with intercept, notrend } \\ U_{i 1}-\left(T^{-1}(t-1)\right) U_{i T} & \text { with intercept and trend }\end{array}\right.$

Im, Pesaran And Shin (IPS)

Im, Pesaran and Shin (1997) used individual ADF regressions for each cross section as follows:

$\Delta U_{i t}=\alpha_{i} U_{i t-1}+\sum_{k=1}^{\rho i} \gamma_{i k} \Delta U_{i t-k}+d^{\prime}{ }_{i t} \delta+\varepsilon_{i t}$

The null hypothesis is $\mathrm{H}_{\mathrm{O}}: \alpha=0$ for all $i$ and the alternative is

$\mathrm{H}_{1}: \begin{cases}\alpha_{i}=0 & \text { for } i=1, \ldots \ldots \ldots . . N \\ \alpha_{i}<0 & \text { for } i=N+1, N+2 \ldots \ldots . N\end{cases}$

Following the estimation of individual ADF regressions, the average of the $t$-statistics for $\alpha_{\mathrm{i}}$ is adjusted to get the desired test-statistic: ${ }^{3}$

$t_{N T}=\left(\sum_{i=1}^{N} t_{i T i}(p i)\right) / N$

where $\mathrm{N}$ is the number of cross sections, and $\mathrm{T}$ is the series length.

When the lag order in equation (15) is non-zero for some cross-sections, the test converges to an asymptotic standard normal distribution when they have been properly standardized:

\footnotetext{
${ }^{3}$ If $p_{\mathrm{i}}=0$ for all $i$, simulated critical values for $\mathrm{t}_{\mathrm{NT}}$ are provided in the IPS paper.
} 


$$
W_{t_{N T}}=\frac{\sqrt{N}\left(t_{N T}-N^{-1} \sum_{i=1}^{N} E\left(t_{i T}\left(p_{i}\right)\right)\right)}{\sqrt{N^{-1} \sum_{i=1}^{N} \operatorname{Var}\left(t_{i T}\left(p_{i}\right)\right)}} \longrightarrow N(0,1)
$$

\subsection{EMPIRICAL RESULTS}

According to the hysteresis of unemployment hypothesis, market rigidities causes cyclical fluctuations to have a permanent effect on employment. In the case of hysteresis, unemployment data is generated by a nonstationary process. To uncover whether the unemployment series is stationary or non-stationary, the study first employs the classical unit root test, followed by the panel unit root tests. Panel A in Table 1 shows the empirical results of the classical intermediate Augmented Dickey-Fuller (ADF) test results with individual effects (a constant) only, while panel B includes individual effects and linear trends. We find that the empirical estimation of individual regions using times series analysis shows mixed results. In panel A of Table 1, the empirical results reject the null that a unit root exists, while we fail to reject the null hypothesis in two of the three regions in panel B. This can be attributed either to the nature of the regions being tested or due to specification error.

Table 1: Individual Unit Root Test: Augmented Dickey Fuller (ADF) Null Hypothesis: Unit root (individual unit root process)

Panel A - Exogenous Variables: Individual Effects

\begin{tabular}{|c|c|c|c|c|}
\hline Series & Probability & Lag & Max Lag & Obs. \\
\hline I495 & 0.0078 & 12 & 14 & 187 \\
\hline SS & 0.0195 & 12 & 14 & 187 \\
\hline BV & 0.0147 & 12 & 14 & 187 \\
\hline
\end{tabular}

Panel B - Exogenous Variables: Individual Effects, Individual Linear Trends

\begin{tabular}{|c|c|c|c|c|}
\hline Series & Probability & Lag & Max Lag & Obs. \\
\hline I495 & 0.0809 & 12 & 14 & 187 \\
\hline SS & 0.1942 & 12 & 14 & 187 \\
\hline BV & 0.1414 & 12 & 14 & 187 \\
\hline
\end{tabular}

Common unit root tests are therefore performed to overcome specification issues. Compared to the classical unit root test (i.e. ADF), panel unit root tests give us a higher degree of heterogeneity. Table 2 presents the empirical estimation of the panel unit root based on the ADF-Fisher, IPS, LLC and Breitung tests. Panel A in Table 2 shows the empirical result with exogenous variables that include individual effects only, while panel B include individual effects and individual linear trends. Probabilities for Fisher tests are computed using an asymptotic Chisquare distribution. IPS, LLC and Breitung tests assume asymptotic normality. The data were available monthly; so a lag length of 12 was chosen. Selection of lags is based on the Schwarz criterion (SIC). The regression also uses the Newey-West bandwidth selection using the Bartlett-Kernel method. 
Table 2: Common Unit Root Tests

Panel A: Exogenous Variables: Individual Effects

\begin{tabular}{|c|c|c|}
\hline Method & Statistics & Obs. \\
\hline \multicolumn{3}{|c|}{ Null: Unit root (assumes common unit root process) } \\
\hline Levin, Lin \& Chu t* & $-4.10902 * * *$ & 561 \\
\hline Breitung t-stat & $-1.05535^{*}$ & 558 \\
\hline \multicolumn{3}{|c|}{ Null: Unit root (assumes individual unit root process) } \\
\hline Im, Pesaran and Shin W-stat & $-1.94822 * *$ & 561 \\
\hline ADF - Fisher Chi-square & $12.2192 *$ & 561 \\
\hline
\end{tabular}

Panel B: Exogenous Variables: Individual Effects, Individual Linear Trends

\begin{tabular}{|c|c|c|}
\hline Method & Statistics & Obs. \\
\hline \multicolumn{3}{|c|}{ Null: Unit root (assumes common unit root process) } \\
\hline Levin, Lin \& Chu t* & $-5.10709 * * *$ & 561 \\
\hline Breitung t-stat & $-2.06876^{* *}$ & 558 \\
\hline \multicolumn{3}{|c|}{ Null: Unit root (assumes individual unit root process) } \\
\hline Im, Pesaran and Shin W-stat & $-3.67044 * * *$ & 561 \\
\hline ADF - Fisher Chi-square & $26.0239 * * *$ & 561 \\
\hline
\end{tabular}

Note: $* * *, * *, *$ denote significance at $1 \%, 5 \%$, and 10\%, respectively. Probabilities for Fisher tests are computed using an asymptotic Chi-square distribution. All other tests assume asymptotic normality. Selection of lags based on SIC. Newey-West bandwidth selection using Bartlett kernel

In looking at all the results in Table 2, the empirical evidence appears not to favor the hysteresis hypothesis. In panel A of Table 2, the individual unit root processes of IPS W-statistics and ADF-Fisher Chi-Square statistics with individual effects strongly rejects the null that a unit root exists at the 5\% and $10 \%$ level respectively. Common unit root tests of Breitung (t-statistics at the 10\% level) and LLC ( $\mathrm{t}^{*}$-statistics at the $1 \%$ level) with a constant also reject the null of the presence of unit roots. In Panel B of Table 2, the IPS, ADF-Fisher and LLC strongly reject the null that a unit root exists at the $1 \%$ level. Common unit root tests of Breitung reject the null of the presence of unit roots at the 5\% level. Overall empirical results using all four panel unit root tests using regional data for the state of Massachusetts reject the hypothesis of a unit root in unemployment rates. This result is consistent with Song and Wu's (1997) study that found evidence against the hysteresis hypothesis for the 48 states in the United States. Leon-Ledesma (2002) in comparing U.S. and the EU using IPS test also rejected the unemployment hysteresis hypothesis in the U.S.

Based on the empirical results refuting unemployment hysteresis, two inferences can be made on the nature of the labor market in the state of Massachusetts. First, in the 1990s many private institutions joined the government programs to create flexibility of the labor market by making available their websites for public access. These websites disseminate information about job openings to better match workers. Thus, labor market flexibility increases flow of information about vacancies, reduces search time and enhances job finding rate. Second, Massachusetts is strategically located in the New England area; one of the regions in the U.S. at the forefront of the internet boom. Majority of job lost in the state of Massachusetts were white collar that are intrinsically occupied by educated workers. These workers have high mobility and flexibility to be easily reemployed.

In summary, the primary goal of this study was to find whether the unemployment data for the state of Massachusetts is stationary or non-stationary. Based on the empirical estimation, we strongly reject a unit root, thus rejecting the unemployment hysteresis hypothesis. Rejecting hysteresis entails that the unemployment dynamic in the state of Massachusetts is a stationary process that is flexible enough to easily revert to its long run equilibrium. 


\subsection{CONCLUSION}

The majority of studies that used conventional unit-root tests especially in the OECD countries support the hysteresis hypothesis. However, few studies that concentrate on the US rejected the unemployment hysteresis hypothesis. In this study, we test hysteresis effects in unemployment using ADF-Fisher, IPS, LLC and Breitung panel unit root tests for three regions in the state of Massachusetts. The outstanding aspect of the panel unit roots tests is that it provides a greater degree of heterogeneity compared to the traditional unit root tests. Based on the empirical results, we strongly reject a unit root in the unemployment rates, refuting the unemployment hysteresis hypothesis.

\section{REFERENCES}

1. Blanchard, O.J. and Summers, L.H., 1986, Hysteresis and the European Unemployment Problem, en S Fisher (ed.), NBER Macroeconomic Annual, MIT Press, Cambridge, MA.

2. Blanchard, O.J. and Wolfers, J., 2000, The Role of Shocks and Institutions in the Rise of European Unemployment: The Aggregate Evidence, Economic Journal, Vol. 110, 462, March, C1-C33.

3. Breitung, J., 1994, Some Simple Tests of the Moving Average Hypothesis, Journal of Time Series Analysis, 15, 31-359.

4. 2000, The Local Power of Some Unit Root Tests for Panel Data, in B. Baltagi, (ed), Nonstationary Panels, Panel Cointegration, and Dynamic Panels, Advances in Econometrics, Vol.15, JAI Press, Amsterdam, pp.161-78.

5. Hall, R.E., A Theory of the Natural Unemployment Rate and the Duration of Unemployment, Journal of Monetary Economics, April 1979, 5, 153-70.

6. Im, K.S., Pesaran, M.H., and Shin, Y., 1997, Testing For Unit Roots in Heterogeneous Panel, Department of Applied Economics, University of Cambridge.

7. Lampe, D.R., (Ed.), 1988, The Massachusetts Miracle: High Technology and Economic Revitalization, The MIT Press, Cambridge MA.

8. Layard, R., Nickell, S.J. and Jackman, R., 1991, Unemployment, Macroeconomic Performance and the Labor Market, Oxford University Press.

9. Leon-Ledesma, M.A., 2002, Unemplyment Hysteresis in the US and EU: A Panel Data Approach, Bulletin of Economic Research, 54(2) pp.94-102.

10. Levin, A., and Lin, C.F., 1992, Unit Root Tests in Panel Data: Asymptotic and Finite Sample Properties, UC San Diego, Working Paper 92-23.

11. Levin, A., Lin, C.F., and Chu, J., 2002, Unit Root Tests in Panel Data: Asymptotic and Finite-Sample Properties, Journal of Econometrics, Vol. 108, pp.1-24.

12. Lindberg and Snower, 1988, Cooperation, Harassment and Involuntary Unemployment: An InsiderOutsider Approach, American Economic Review, 78(1),Vol. 110, 462, March, C1-C33.

13. Maddala, G.S., and Wu, S., 1999, A Comparative Study of Unit Root Tests with Panel Data a New Simple Test, Oxford Bulletin of Economic and Statistics, Special Issue, Vol. 61, pp. 631-652.

14. Mitchell, W.F., 1993, Testing for Unit Root and Persistence in OECD Unemployment Rates, Applied Economics, Vol.25, pp.1489-1501.

15. Moon, H.R., Perron, B., and Phillips, P.C.B., 2006, On the Breitung Test for Panel Unit Roots and Local Asymptotic Power, Econometric Theory Notes and Problems, forthcoming.

16. Nelson, C.R. and Plosser, C.I., 1982, Trends and Random Walks in Macroeconomic Time Series, Journal of Monetary Economics, 10, pp. 139-162.

17. Perron, P., 1989, The Great Crash, The Oil Price Shock and the Unit Root Hypothesis, Econometrica, Vol.57, pp.1361-1401.

18. Phelps, E.S., 1972, Inflation Policy and Unemployment Theory. The Cost-Benefit Approach to Monetary Planning, Macmillan.

19. 1994, Structural Slumps-The Modern Theory of Unemployment, Interest and Assets, Cambridge, MA: Havard University Press.

20. 1999, Behind the Structural Boom, the Role of Assets Valuations, American Economic review, Vol.89, pp63-68. 
21. Roed, K.,1996, Unemployment Hysteresis-Macroevidence from 16 OECD countries, Empirical Economics, Vol.21, pp.529-600.

22. Song,F.M. and Wu, Y., 1997, Hysteresis in Unemployment: Evidence from 48 States, Economic Inquiry, Vol.35, pp. 235-244.

\section{NOTES}

